\title{
Obesity Management-Bariatric Surgery vs Lifestyle Modification
}

\author{
Poondy G. R. Raman ${ }^{1}$, Subodh Banzal ${ }^{2}$ \\ ${ }^{1}$ MGM Medical College, Indore, India \\ ${ }^{2}$ Shri Aurobindo Institute of Medical Sciences, Indore, India \\ Email: drpgraman@yahoo.com
}

Received December 2, 2012; revised January 3, 2013; accepted February 5, 2013

\begin{abstract}
Role of Bariatric surgery for obesity is briefly outlined. Selection criteria, contraindications, evaluations of patients before surgery, types of bariatric surgery with their merits and demerits are discussed. Results of lifestyle modifications is compared with that of bariatric surgery.
\end{abstract}

Keywords: Types of Bariatric Surgery; Selection Criteria; Contraindication; Merits and Demerits; Lifestyle Modification

\section{Introduction}

Bariatric surgery is becoming more popular for morbid obesity. Not only it helps in rapid weight reduction but also improves co-morbid conditions, like diabetes and hypertension. With lifestyle modification weight loss is gradual. Often it is difficult for the obese to follow lifelong lifestyle modification. Hence compliance is poor. Surgery for obesity is the last option but is most effective. Life-long medical surveillance is needed to prevent micronutrient and vitamin deficiencies after surgery. Conservative treatment is less effective than bariatric surgery in terms of weight reduction.

\section{Criteria for Selection for Bariatric Surgery}

BMI -35 to $40 \mathrm{~kg} \cdot \mathrm{s} / \mathrm{m}^{2}$ with significant co-morbid diseases or obesity with BMI $>40 \mathrm{kgs} / \mathrm{m}^{2}$; well informed, motivated patient who understands and accepts risk of surgery; long-time commitment to life-style changes and follow-up; supportive social environment and absence of psychosis or depression are the usual criteria for selection for bariatric surgery.

\section{Contra Indications}

- Severe mental or cognitive disorders

- Severe non-stabilized feeding behaviour disorders

- A foreseeable incapacity on the part of the patient to participate in a long-term medical follow-up

- Dependence on alcohol and other toxic substances

- Absence of previous medical management

- Diseases which influence the short term and mid-term vital prognosis

- Contraindications for general anesthesia

\section{Essential Points for Bariatric Surgery}

- It is recommended that the medico-surgical team suggest the technique, the principles, the benefits, the risks and inconveniences of each technique and the possibility of recourse to repair surgery after weight loss to patient.

- Patient should have understood the necessity of modifying his feeding behaviour, his life style, and of adhering to a follow-up all through life.

- Patient may be given a booklet giving information about the bariatric surgery.

\section{Evaluation of the Patient before Bariatric Surgery}

- Systemic investigations and management of co-morbidities

- Evaluation of feeding behaviour

- Psychiatric evaluation

- Lab investigation into pre-existing vitamin deficiency

- Upper GI endoscopy to investigate an infection by H. pylori

There are two types of surgeries namely malabsorptive and restrictive (Table 1).

\section{Laparoscopic Adjustable Gastric Banding (LAGB)}

Widely practiced simple surgery with less complications and low mortality $(0.05 \%)$ [1]. Weight is lost slowly but 
Table 1. Types of weight-loss surgeries.

\begin{tabular}{ll}
\hline \multicolumn{1}{c}{ Mal absorptive } & \multicolumn{1}{c}{ Restrictive } \\
\hline Jejuno ileal bypass & Vertical banded gastroplasty \\
$\begin{array}{l}\text { Bilio pancreatic diversion \& } \\
\text { duodenal switch }\end{array}$ & $\begin{array}{l}\text { Laparoscopic adjustable gastric } \\
\text { band }\end{array}$ \\
& Gastric bypass \\
\hline
\end{tabular}

for prolonged period. Restrictive procedures, hence vitamin deficiency is not common as there is intact GI tract. Folic acid deficiency has been seen due to different eating habits after surgery viz. taking less fruits, vegetables and whole-meal bread. Patient has to take 4 - 6 small feeds to avoid vomiting or intense pain which usually occurs if one eats a heavy meal. Re-operation is less, results are good. Complications of this surgery are-prolapse of gastric wall through the band with acute stromal obstruction and vomiting. Devise erosion and devise malfunction.

\section{Laparoscopic Gastric Bypass Surgery (RNY)}

Complex and major surgery for those whose BMI is over 40. Significant weight loss occurs in 18 months. There is evidence that surgery can help to achieve complete remission, especially in morbid obese patients with diabetes. It is not effective in T2 DM with low BMI [2]. Elderly patients with T2 DM with a prolonged duration were less likely to achieve euglycemia at 12 months. Higher rates of remission is seen in diabetic patients with shorter duration. Complete remission was observed with BMI above 32 [3]. This surgery carries a mortality rate of 0.4. Rouen Y Gastric Bypass in women with polycystic ovarian syndrome is effective in alleviating symptoms [4].

\section{Mechanism of DM Control in RYGB (Roux-en-Y Gastric Bypass)}

Nutrients reach the distal ileum within 5 minutes of ingestion of food and this stimulates the secretion of GLP1 by L cells located in this area [5].

\section{Sleeve Gasterectomy (Gastric Sleeve or Sleeve Resectomy, VSG)}

Done in patients with BMI over 35. Involves removing a major portion of the stomach. Once done, this surgery is not reversible. It is a type of restrictive surgery. First described by Hess in 1988. It provides acceptable percentage of weight loss $(70 \%-80 \%)$. Late nutritional complications occur after this surgery [6]. Main complications are diarrhoea, hepatic failure, metabolic derangement, protein malnutrition, iron deficiency anaemia, vitamin deficiency and metabolic bone diseases.

\section{Vertical Banded Gastroplasty (VBG) [7]}

A small pouch of stomach, is created with gastric banding (stomach stapling). Revisional surgery is needed in VBG due to stoma, stenosis, pouch enlargement or stapler dysfunction. Long-term weight loss and improved co-morbidities occur. In $65 \%$ of cases, there is failure of surgery and need revision and conversion surgeries.

\section{Jejuno Ileal Bypass [7]}

JIB is created by division of proximal jejuno distal to ligament of Terez, creating anaestomosis to Ileum $10 \mathrm{~cm}$ from ileocaecal valve.

Procedure creates short-gut syndrome. It becomes a malabsorptive procedure and results in weight loss. Patient develops nephrolithiasis, dental caries, renal failure, bypass enteritis, cirrhosis, hepatic failure, arthritis and severe metabolic deficiency.

Weight loss occurs with all types of bariatric surgery from a minimum of 47.5 to maximum of $70 \%$. Weight losses with different bariatric surgery are shown in Table 2.

Amelioration of co morbid condition occurs mainly with JIB given below (Table 3).

Risk of T2DM and CAD risk factors reduced after gastric bypass and not after restrictive surgery.

\section{Benefits of Bariatric Surgery [8]}

- Appetite decreases

- Weight loss of $70 \%$ of excess of body weight ${ }^{*}$ occurs

- $70 \%$ patients can stop blood pressure medication

Table 2. Effect of bariatric surgery on weight loss (EWL).

\begin{tabular}{cc}
\hline Type of surgery & Percentage weight loss (EWL) \\
\hline All types of surgery & 61.2 \\
Gastric banding & 47.5 \\
Gastric bypass & 61.2 \\
Gastroplasty & 68.2 \\
BPD/DS & 70 \\
\hline
\end{tabular}

Table 3. Effect of bariatric surgery on weight loss and amelioration of comorbid conditions [7].

\begin{tabular}{|c|c|c|}
\hline $\begin{array}{l}\text { Type of bariatric } \\
\text { surgery }\end{array}$ & $\begin{array}{l}\text { Weight loss } \\
\text { after } 2 \text { years }\end{array}$ & $\begin{array}{l}\text { Comorbid conditions corrected } \\
\text { after JIB }\end{array}$ \\
\hline RYGB & $30 \%$ & $\begin{array}{l}\text { 70\% dyslipidemia } \\
\text { 70\% hypertension }\end{array}$ \\
\hline GB & $20 \%$ & $\begin{array}{c}\text { Obstructive sleep apnoea improved } \\
\text { 90\% T2DM reverted }\end{array}$ \\
\hline BPT & $35 \%$ & $\begin{array}{c}\text { Gastro oesophageal reflex } \\
\text { Cured in } 100 \%\end{array}$ \\
\hline
\end{tabular}

"Percentage excess weight loss is-weight loss/total weight-normal weight (EWL). Expected EWL after bariatric surgery is $50 \%-70 \%$. 
- Lipids come to normal in $70 \%$ of patients with dyslipidemia

- GERD is completely cured

- $90 \%$ of type-2 DM become euglycemic

- Sleep apnea syndrome is completely cured

- Long-lasting effect on weight and co-morbidities Various hormonal changes occur after bariatric surgery (Table 4).

Long term complication are more with LAGB (Table 5).

\section{Complications of Gastric Bypass}

- Anastomosis leakage, stricture and ulcer

- Perforation and peritonitis

- Thrombo embolic complications

- Dumping syndrome

- Nutritional deficiencies

- Iron, Zinc, B1, Vitamin B12 (due to lack of intrinsic factor), Pica develop due to iron deficiency

- Infection

- Haemorrhage

- Hypo parathyroidism is due to inadequate calcium absorption
- Hypochlorohydria leads to positive hydrogen breath test which is due to bacterial overgrowth in small bowel

- Muscle weakness due to protein deficit

- Psychological problems like depression Comorbidity resolution is greatest with BPD and DS (Table 6).

Describes comorbodity resolution with sleeve gastrictomy(Table 7).

Systolic/Diastolic BP, Plasmaglucose, HbA1C, Total cholesterol and triglyceride, all above parameters decreased to normal after bariatric surgery.

Clinically beneficial weight loss in patients with morbid obesity is possible with conservative non-surgical interventions particularly residential intermittent program and weight loss camps. Despite much larger weight loss observed in surgical group, small weight losses of 5\% $15 \%$ achieved through life-style intervention can result in similar reduction in risk factors and resolution of comorbidities at one year [12].

Compares lifestyle modifications with bariatric surgery (Table 8 ).

Table 4. Hormonal changes after bariatric surgery [9].

\begin{tabular}{lcc}
\hline & & Changes Seen \\
\cline { 2 - 3 } Hormone/Peptide & Post bariatric surgery & Obesity \\
\cline { 2 - 3 } Ghrelin & Increased & Increased \\
Post Prandial PYY & Increased & Decreased \\
GLP-1 & Increased & Increased \\
Enteroglucagon & Increased & Decreased \\
GIP & Decreased & Increased \\
C-Peptide & Decreased & Increased \\
Adiponectin & Increased & Decreased \\
Leptin & Normalises & Increased \\
Resistin & Decreased & Increased \\
TNFA & Decreased & Increased \\
IL-6 & Decreased & Increased \\
Plasminogen Activator Inhibitor-I (PAI-I) & Decreased & Increased \\
\hline
\end{tabular}

Table 5. Long-term complications of bariatric surgery [10].

\begin{tabular}{cccc}
\hline Complications & LAGB & VBG & RYGB \\
\hline Reflux & $6 \%$ & $6 \%$ & $0 \%$ \\
Vomiting & $42 \%$ & $41 \%$ & $0 \%$ \\
Dysphagea & $2 \%$ & $6 \%$ & $4 \%$ \\
Port related problem & $10 \%$ & $0 \%$ & $0 \%$ \\
Re-operation & $33 \%$ & $26 \%$ & $8 \%$ \\
Conversion & $10 \%$ & $63 \%$ & $0 \%$ \\
Second re-operation & $5 \%$ & $8 \%$ & $0 \%$ \\
\hline
\end{tabular}


Table 6. Comorbidity resolution [11].

\begin{tabular}{|c|c|c|c|c|c|}
\hline Resolution criteria & Gastric banding & Gastroplasty & Gastric bypass & BPD and DS & Total \\
\hline EWL & $47 \%$ & $68 \%$ & $62 \%$ & $70 \%$ & $61 \%$ \\
\hline Mortality & $0 \%$ & $0.1 \%$ & $0.5 \%$ & $1.1 \%$ & \\
\hline Resolution of DM & $48 \%$ & $72 \%$ & $84 \%$ & $99 \%$ & $77 \%$ \\
\hline Resolution of hyper-lipidemia & $50 \%$ & $74 \%$ & $97 \%$ & $99 \%$ & $79 \%$ \\
\hline Hypertension & $43 \%$ & $69 \%$ & $68 \%$ & $83 \%$ & $62 \%$ \\
\hline Sleep apnea syndrome & $95 \%$ & $78 \%$ & $80 \%$ & $92 \%$ & $86 \%$ \\
\hline Resolution of fatty liver & $\begin{array}{l}\text { Improved with all } \\
\text { surgeries }\end{array}$ & $\begin{array}{l}\text { Improved with all } \\
\text { surgeries }\end{array}$ & $\begin{array}{l}\text { Improved with all } \\
\text { surgeries }\end{array}$ & $\begin{array}{l}\text { Improved with all } \\
\text { surgeries }\end{array}$ & $\begin{array}{l}\text { Improved with } \\
\text { all surgeries }\end{array}$ \\
\hline
\end{tabular}

Table 7. Comorbidities resolved or improved after laparoscopic sleeve gastrectomy [12].

\begin{tabular}{|c|c|c|c|c|}
\hline Comorbidity & No. of patients & Resolved & Improved & $\%$ \\
\hline Hypertension & 119 & 81 & 35 & 97.5 \\
\hline $\mathrm{DM}$ & 58 & 41 & 16 & 98.3 \\
\hline Hyperlipidemia & 98 & 47 & 48 & 96.3 \\
\hline Depression & 103 & 41 & 61 & 99.0 \\
\hline Obstructive sleep apnea & 73 & 53 & 18 & 97.3 \\
\hline GERD & 113 & 43 & 69 & 99.1 \\
\hline Arthritis & 72 & 37 & 34 & 98 \\
\hline Chronic joint pains & 44 & 26 & 18 & 100 \\
\hline Stress inconvinence & 44 & 41 & 3 & 100 \\
\hline Asthma & 34 & 21 & 13 & 100 \\
\hline
\end{tabular}

Table 8. Comparison between life-style modification and bariatric surgery [13].

\begin{tabular}{|c|c|c|}
\hline Features & Life-style modification & Bariatric surgery \\
\hline Cost & No cost & Costly \\
\hline Weight loss & Long term results, moderate loss & Severe weight loss in short time \\
\hline Nutrient deficiency & No & Usually occurs \\
\hline Effect on comorbid disorders & Mild to moderate & Marked amelioration to cure \\
\hline Psychological problems & No & Can occur \\
\hline Patients cooperation & $\begin{array}{l}\text { Needed, motivated to continue life-style } \\
\text { modification for ever }\end{array}$ & Not needed \\
\hline Food habits & Must learn to eat healthy foods & $\begin{array}{l}\text { Must learn to eat slowly and } 4 \text { - } 6 \text { small feeds to } \\
\text { prevent vomiting and epigastric pain }\end{array}$ \\
\hline Post-operative complications & Not applicable & $\begin{array}{l}\text { Can develop. Needs revision or redo surgeries at } \\
\text { times }\end{array}$ \\
\hline Useful & In all age groups & $\begin{array}{l}\text { Not much effective with low BMI, oldage and with } \\
\text { long-duration of comorbid disorders }\end{array}$ \\
\hline
\end{tabular}




\section{Cardiovascular Outcomes after Bariatric Surgery [14-16]}

Swedish obese subject study looked into cardiovascular outcomes after bariatric surgery. Patients have followed for 2 to 10 years. There were 2000 surgically treated patients for obesity who are compared with 2000 controlled subjects with life-style modification. In surgically treated cases, normalization of Triglyceride, Hyperglycemia of Diabetes, Hyperuricemia were seen.

Despite reduction in disease related deaths after gastric bypass, surgery risk of non disease related deaths such as accidents and suicides increased as compared to control group due to psychological problems [17].

\section{Pregnancy after Bariatric Surgery}

Pregnancy after bariatric surgery is not exception; it is even anticipated, taking into account the prevalence of obesity in women of a reproductive and women having recourse to surgery and the possible improvement in fertility after surgery. Pregnancy has better prognosis after surgery.

- Contraception is recommended as soon as surgery is planned, and thereafter generally for 12 to 18 months after the intervention.

- Investigation into vitamin and nutritional deficiencies should be systematic and best done beore planning for any pregnancy. Supplements of iron, folates, vitamin B12, vitamin D and calcium must be instituted in case of pregnancy after a malabsorptive surgery. For any type of surgery, supplements of folates must be instituted as soon as a pregnancy is desired.

\section{Conclusions}

Various types of surgeries done in morbid obesity are described with their merits ad demerits. Resolution of comorbid diseases with obesity occurs depending upon the amount of weight loss, age of the patients, and duration of comorbid disorders. Low BMI patients may not fully benefit by these surgeries. After malabsorptive surgeries, patient has to be on life-long vitamin supplement and often after bariatric surgery patient has to take small 4 - 6 frequent meals as large meal ingestion will lead to vomiting and intense abdominal pain. Even in restrictive surgery, patient needs folic acid supplement. Hormonal changes after bariatric surgery are described. Bariatric surgery is compared with lifestyle modification.

It seems bariatric surgery is useful in morbid obesity with comorbid conditions where lifestyle modification has failed or patient is unable to do. For other obese patients lifestyle modifications should be preferred treatment.

\section{REFERENCES}

[1] A. E. Chapman, G. Kiroff, P. Game, et al., "Laparoscopic
Adjustable Gastric Banding in the Treatment of Obesity: A Systematic Literature Review," Surgery, Vol. 135, No. 3, 2004, pp. 326-351. doi:10.1016/S0039-6060(03)00392-1

[2] A. Hussain, H. Mahonad and S. Elltasan, "Can Roux-EnY Gastric by Pass Provide a Life-Long Solution for Diabetes Mellitus?” Canadian Journal of Surgery, Vol. 52, No. 6, 2009, pp. 269-275.

[3] C. K. Huang, C. H. A. Shobin, H. N. Lo, et al., "Laparoscopic Roux-en-Y Gastric by Pass for the Treatment of Type-2 DM in Chinese Patients with BMI of 25 - 35," Journal of Metabolic Surgery and Allied Care, Vol. 21, No. 9, 2011, pp. 1344-1349.

[4] G. M. Eid, D. R. Cottam, L. M. Veleu, et al., "Effective Treatment of Polycystic Ovarian Syndrome with Rouxen-Y Gastric Bypass,” Surgery for Obesity and Related Disorder, Vol. 1, No. 2, 2005, pp. 77-80.

[5] E. Mason, "Mechanism of Surgical Treatment of Type-2 DM,” Obesity Surgery, Vol. 15, No. 4, 2005, pp. 459-461. doi:10.1381/0960892053723330

[6] D. S. Hess, "Hess DW1998-Biliopancreatic Diversion with a Duodenal Switch,” Obesity Surgery, Vol. 8, No. 3, 1998, pp. 267-282.

[7] G. W. Strain, M. Gagner, A. Pomp, et al., "Comparison of Weight Loss and Body Composition Changes with Four Surgical Procedures," Surgery for Obesity and Related Diseases, Vol. 5, No. 5, 2009, pp. 582-587.

[8] G. S. Jakobsen, D. Hofso, J. Roislien, R. Sandbu and J. H. Mesaeth, "Morbid Obesity Patients-Who Undergoes Bariatric Surgery?” The Journal of Metabolic Surgery \& Allied Care, Vol. 20, No. 8, 2009, pp. 1142-1148.

[9] M. Guldstrand, "Hormonal Changes after Bariatric Surgery,” Endocrine Abstracts S23.3, 2010.

[10] C. P. Bernert, C. Ciangura, M. Coupaye, S. Czernichow, J. L. Bouillot and A. Basdevant, "Nutritional Deficiency after Gastric Bypass: Diagnosis, Prevention and Treatment," Diabetes \& Metabolism, Vol. 33, No. 1, 2007, pp. 13-24.

[11] B. G. Luck, B. Movitz, S. Jansma, et al., "Laparoscopic Sleeve Gastrecomy Is Safe and Effective Bariatric Procedure for the Lower BMI Population," The Journal of Metabolic Surgery and Allied Care, Vol. 21, No. 8, 2010, pp. 1168-1171.

[12] H. Buchwald, Y. Avidor, E. Braunwald, et al., "Bariatric Surgery: A Systematic Review and Meta-Analysis," JAMA, Vol. 292, No. 14, 2004, pp. 1724-1737.

[13] H. Bjorvell and S. Rossner, "A Ten-Year Follow-Up of Weight Change in Severely Obese Subjects Treated in a Combined Behavioural Modification Programme," International Journal of Obesity, Vol. 16, No. 8, 1992, pp. 623625.

[14] V. G. Athyros, K. Tziomalos, A. Karagiannis and D. P. Mikhailidis, "Cardiovascular Benefits of Bariatric Surgery in Morbidly Obese Patients,” Obesity Review, Vol. 12, No. 7, 2011, pp. 515-524.

[15] J. A. Batsis, A. Romero-Corral, M. L. Collazo-Clavell, M. G. Sarr, V. Somers, L. Brekke and F. Lopez-Jimenez, "Effect of Bariatric Surgery on Cardiovascular Risk Factors and Predicted Effect on Cardiovascular Events and 
Mortality in Class II-III Obesity," Journal of the American College of Cardiology, Vol. 47, No. 4, 2006, p. 358A.

[16] L. Sjöström, A.-K. Lindroos, M. Peltonen, J. Torgerson, C. Bouchard, B. Carlsson, S. Dahlgren, B. Larsson, K. Narbro, C. D. Sjöström, M. Sullivan and H. Wedel, "Swedish Obese Subjects Study Scientific Group," The New England Journal of Medicine, Vol. 351, 2004, pp. 2683-
2693. doi:10.1056/NEJMoa035622

[17] T. D. Adams, R. E. Gress, S. C. Smith, R. C. Halverson, S. C. Simper, W. D. Rosamond, M. J. LaMonte, A. M. Stroup and S. C. Hunt, "Long Term Mortality after Gastric Bypass Surgery,” The New England Journal of Medicine, Vol. 357, No. 8, 2007, pp. 753-761. 